\title{
The Role of Responsible HRM Practices and a Culture-Related Capability on the CSR-Performance Association: A Small Firm Perspective
}

\begin{abstract}
This chapter focuses on the role that responsible human resource management practices (HRM) play in relation to proactive corporate social responsibility (CSR) and its impact on firm performance, using evidence from small firms in the Australian manufacturing industry. The empirical evidence reveals the critical moderating contribution of responsible HRM practices in the implementation of proactive CSR and enhancement of financial performance in small firms. The study findings indicate the need for managers of small firms, who wish to boost financial competitiveness through proactive CSR, to adopt responsible HRM practices that avoid a directive approach and which foster employee participation and engagement. It is suggested that this can be done by leveraging the relative informality of work organisation and familial ties that help engender trust and reciprocity in small firms.
\end{abstract}

Please cite as:

O'Donohue, W. and Torugsa, N. 2014. The Role of Responsible HRM Practices and a CultureRelated Capability on the CSR-Performance Association: A Small Firm Perspective, in C. Machado and J. P. Davim (eds.), Work Organization and Human Resource Management, Springer International Publishing, Switzerland (DOI: 10.1007/978-3-319-06376-8_1) 


\title{
The Role of Responsible HRM Practices and a Culture-Related Capability on the CSR-Performance Association: A Small Firm Perspective
}

\author{
1 Introduction \\ In today's business climate, a singular emphasis by firms on management practices that \\ maximise profitability, whilst ignoring their wider negative impacts over the long-term, is \\ considered generally no longer acceptable. Increasingly, firms regardless of size are being \\ expected to recognise their social responsibility, take the initiative, and contribute towards \\ sustainability $[1,2]$. This implies the necessity for firms in today's highly competitive \\ business environment to adopt management practices that deliver not only superior \\ financial performance but also create sustainable outcomes of value that meet societal \\ expectations [3]. The role played by a firm's human resource management (HRM) practices \\ in relation to sustainability and social responsibility, and its impact on firm performance has \\ received broad research attention in the literature [4-6]. If HRM in general terms is \\ considered to be the 'productive use of people in achieving the organization's strategic \\ objectives and the satisfaction of individual employee needs' [7], there is still much to learn \\ about the process through which a firm's HRM practices interact with other organisational \\ practices to deliver performance outcomes that result in competitive advantage and \\ superior financial returns for the firm [6].
}

This paper addresses that gap in understanding by examining the moderating contribution of a firm's HRM-considered in terms of responsible practices and a culture related capability - to the implementation of corporate social responsibility (CSR) for generating an improvement in business financial performance, using evidence from small firms in the machinery and equipment sector of the Australian manufacturing industry. For the purpose of this study, the number of employees is used to determine firm size [8]; hence in line with previous research $[9,10]$, a small firm is defined as having an upper limit of less than 100 employees. Firms of this size are of interest because the role of HRM as a moderating influence on the CSR-performance association is under-researched when compared to medium and large sized firms $[11,12]$.

\section{Role of HRM in the CSR-Performance Association}

Many HRM scholars contend that effective management of a firm's human resource capability is fundamental to the achievement of sustainable and socially responsible outcomes; indeed, CSR sits at the very heart of their conception of HRM as an essential organisational practice. Advocates of this view contend that the three principles of sustainability form the nexus between high quality management of a firm's human resources and the creation of high quality transparent and ethical relationships both inside and external to the firm. This nexus is held to operate in all firms regardless of size $[6,13-$ 16]. Before considering the role of HRM let us make clear some of the definitional boundaries within which the discussion will occur.

\subsection{Corporate Social Responsibility and Financial Performance}

Whilst definitions of corporate social responsibility and sustainability might originally have differed, there has in recent years been a convergence of meaning in the literature to the point where the terms may be used interchangeably $[2,17]$. Given this convergence, in this paper we have chosen to use the term 'corporate social responsibility' (CSR) defined as 
responsible management practices that support the three principles of sustainability: economic growth and prosperity, social cohesion and equity, and environmental integrity and protection [18]. Under this definition, if firms are to meet their societal responsibilities and deliver sustainability, a responsible management approach is required; one which acknowledges the need for profitability, but at the same time takes an integrated, holistic perspective that emphasises outcomes and practices that support the three principles of sustainability equally and satisfies a broad range of stakeholders $[2,18]$. In a competitive business environment simply maintaining a reactive stance to CSR-related legal requirements, with management practices that aim solely at achieving regulatory compliance and maintaining legitimacy, arguably will not suffice; instead, adoption of a range of responsible proactive management practices that support the economic, social and environmental principles of sustainability has been advocated as being a significant priority for firms seeking a competitive advantage and enhanced performance [19-24]. It is this 'proactive' form of CSR (i.e. voluntary adoption of responsible management practices that go beyond regulatory and legitimacy requirements, in order to enhance firm performance as well as contribute broadly and positively to society) that is of interest in this study [25, 26].

Responsible management embracing the principle of economic sustainability connects most directly to a firm's profitability [18]. Characteristically, such management practices eschew a narrow focus on managing short-term financial performance (profit maximising) and emphasize active management of long-term economic performance issues that are important, not just for the firm but for all stakeholders in its host community. In terms of purpose, economic-related CSR aims, for example, at encouraging innovation, efficiency, and the effective creation and sustainable management of a firm's economic capital, thereby fostering longevity in profitability and growth. Firms engaging in proactive management of economic-related CSR issues deliberately pay attention to a range of matters such as innovative capability, product quality, fair pricing, and supply chain management from sourcing to final payment [27-29].

Responsible management supporting the environmental principle of sustainability focuses generally on eco-efficiency and pollution prevention, and aims at minimising the firm's ecological footprint at all points in its product life cycle [30]. Such activity is often characterized by adoption of internationally standard environmental management systems (or a total quality environmental management approach) that ensure a firm's environmental impacts are monitored and managed systematically rather than on an ad hoc basis [31]. Systematic environment-related CSR helps build a firm's credibility among its external stakeholders, as well as ensure that the principle of environmental sustainability is institutionalized among employees [30].

Turning to the third CSR principle of social sustainability, responsible management in this dimension can be categorised as having either an external focus on the broader community, or an internal focus on the workplace and employees [18]. Accordingly, social-related CSR that focuses on the link between the firm and its external community, such as philanthropic and corporate citizenship initiatives, is informed by the general value systems, norms and pressures which dominate social community networks in which firms operate $[3,32,33]$. At the same time, social-related CSR reflects a focus in the workplace on the health, safety, and personal and professional well-being of employees; it is the mechanism through which 
internal workplace human resource issues, such as work/life balance, employee participation in decision making process, and diversity and equal opportunity, are managed $[18,32,34]$.

The amount of empirical research examining the effectiveness of the proactive form of CSR as a business management practice that delivers superior financial returns is limited but growing. To date, whilst the research overall has demonstrated that CSR can impact positively on financial performance, much of the research has been conducted with a specific and narrow focus on environmentally related CSR and mainly in large firms [35-37]. This focus is similar in the much less studied small firm context, where quantitative research has found a positive link between financial performance and proactive CSR (in its environmental dimension). In addition, a qualitative study of social- and environmentrelated CSR has reported that small firms can derive not only quantifiable benefits (e.g. cost savings and increased profitability) but also, and in the main, a range of intangible benefits (e.g. improved image and reputation, and enhanced trust) [34]. These research findings, in line with other studies of firm performance in the literature, show that embedding the economic, social and environmental principles of sustainability in proactive management practices, can accrue non-material benefits to the firm, such as social approval and reputation building, improved customer relationships, and increased access to resources, all of which together positively influence firm performance $[2,20,21,27,38]$.

Most recently and of specific interest here, Torugsa and colleagues have presented evidence indicating proactive CSR has a positive effect on financial performance in small and medium enterprises (SMEs); they also found that the influence of each of the three CSR dimensions is positively moderated by an interactive process between the three dimensions of CSR [26]. Based on their results, they concluded that SMEs should pay primary attention to economicrelated proactive CSR, while simultaneously and selectively focusing on supportive elements of social- and environment related proactive CSR, if sustainable long-term financial performance is to be achieved [26]. In the light of these research findings, this study focuses on the role played by a firm's HRM practices - that is one of the two elements in socialrelated CSR outlined above-in the delivery of CSR performance outcomes that enhance financial returns. Drawing on the HRM and resource-based view literature, we will now discuss and develop some hypotheses regarding the links between responsible HRM practices and the effective adoption of proactive CSR across its three dimensions.

\subsection{Moderating Role of HRM: Responsible Practice and Capability Perspectives}

Basically, the centrality of human resources in CSR is argued on three grounds. Firstly, in terms of the sustainability principle of economic growth and prosperity, ongoing innovation is seen as the major factor that underpins a firm's performance. In particular, evidence for the fundamental role and contribution of a firm's human resource capability in the creation and support of innovation as a competitive advantage has been well documented in the literature $[3,4,16,39,40]$. Similarly, there is much recent empirical research that supports the crucial role played by specific HRM practices (e.g. training and development, talent management, organisational culture and development) in stimulating innovation in support of sustainable outcomes linked to financial performance [14, 41, 42]. 
Secondly, there is research highlighting the importance of human resources in the achievement of environmental sustainability and a firm's performance [14, 43, 44]. Human resource attributes, such as employee attitudes, environmental values, technical and managerial skills have been shown to be fundamental to the development and implementation of proactive environmental CSR [31, 45-47]. Across this research, there is general agreement that high quality HRM practices can motivate and assist employees to adopt and enact the principle of environmental sustainability in their work. The means to this end include managing organisational culture and development so as to integrate environmental sustainability into the firm's values and norms, and demonstration of a credible commitment by the firm to continuous improvement of employee environmental management skills and knowledge.

Thirdly, and perhaps most importantly, the case for the centrality of human resources in CSR is grounded on the significant commonality in issues that responsible HRM practices and social CSR practices in the workplace in particular seek to address. For example, scholars contend that a key human resources concern in today's business environment is internal diversity management; a concern they also identify as being inter alia central to sustainability and a firm's performance [14]. Research also maintains that regeneration of value and the renewal of wealth underpin sustainability; accordingly, issues such as equity, justice, respect, employee consultation, work-life balance, development, and employee wellbeing, all of which are grist for the HRM mill, must be addressed in the pursuit of sustainability and associated improvement in a firm's performance [13, 14, 48]. Building on the HRM literature [49, 50], Shen and Zhu [51] describe the CSRrelated concept of socially responsible human resource management practices that embraces workplace health and safety, equity, work-life balance, employee development, and employee involvement and participation. Finally, Gond and colleagues [52] offer a model (see Fig. 1), which clarifies the relationship between CSR and responsible HRM practices.

Figure 1 indicates there are activities which form a focus solely for HRM or CSR, and these activities are differentiated from other activities that involve mutually supportive actions by one domain to the other. At the heart of the model are those activities common to both domains [52]. Given the consensus in both the CSR and HRM literature, we consider 'social CSR in the workplace' and 'responsible HRM practices' to be in effect one and the same thing; this implies responsible HRM practices are a key moderating factor in the relationship between CSR in all three of its dimensions and a firm's performance generally, and financial performance specifically.

Insert Figure 1 here

In line with the above discussion of the contribution of CSR to financial performance, and the distinction we draw between external social CSR in the community and internal CSR in the workplace (also called responsible HRM practices), we propose the following hypotheses for testing in relation to small firms:

Hypothesis 1: Economic and environmental CSR together with social CSR in the community (EcEnvSoC) is positively associated with financial performance 
Hypothesis 2: Responsible HRM practices (RHRM) positively moderate the association between EcEnvSoC and financial performance in such a way that the positive association is significantly stronger at high levels of RHRM.

In line with the resource-based view of the firm, it is not only a firm's resources (e.g. financial, human and physical) but also its capabilities (i.e. the integrated application of its resources) that drive firm performance $[53,54]$. While a wide variety of specific capabilities that support proactive CSR and financial performance have been discussed in the research literature (such as 'shared vision and employee involvement' $[2,55,56]$; 'stakeholder management' [57]; 'innovation' [58, 59]; 'strategic proactivity' [31]; and 'higher-order learning' [60]), much of the discussion has focused predominantly on capabilities in relation to only one dimension of CSR - the environmental dimension-and its management in large firms. In contrast, in their study of Australian manufacturing SMEs, Torugsa and colleague $[25,26]$ examined three specific capabilities ('shared vision', 'strategic proactivity' and 'stakeholder management') and the association between those capabilities, the adoption of CSR in its three dimensions, and financial performance. They found that these organisational capabilities underpinned the adoption and implementation of proactive CSR as a business strategy that linked to improved financial performance in SMEs. Actions/topics seen as being part of HRM CSR programs/policies involving strong HRM support Actions/topics seen as being part of CSR Transformation of HRM processes to integrate CSR programs/policies

Given our focus on responsible HRM practices in small firms, we restrict our discussion specifically to those two capabilities considered by $[25,26]$ which have been identified most closely in the literature with $\operatorname{HRM}[3,4,61]$. The first of the capabilities-'Shared Vision'exists when the members of a firm have a shared feeling that the firm's objectives are important and that all of its members may contribute to defining them. Such a capability is held to be fundamental to the different parts of a firm being able to bond together and integrate or combine resources effectively [62]. Creating a shared vision that supports proactive CSR entails recognition by a firm of the essential role of responsible HRM practices, and the need for a deep commitment to empowering social processes that generate consensus and significant employee involvement [56,63]. Indeed, many scholars argue that the creation of a shared vision must be a primary goal of responsible HRM practices $[64,65]$.

The second capability - 'Strategic Proactivity' - is realised when a firm, rather than merely reacting to changes in its business environment, uses responsible management practices to shape the environment to its own advantage, and identify and capitalize on new emerging opportunities [1,31, 59, 66-68]. As with the case of shared vision, a strategic proactivity capability is closely linked to a firm's organisational culture which is derived in large part from a purposeful strategic approach to managing its human resources [61]; strategic proactivity requires a commitment to responsible HRM practices that empower, develop and involve employees, as well as encourage and guide employees to think and act proactively in line with the firm's CSR business strategy $[31,68]$. Given the complementarity of these two capabilities and their importance as a focus for responsible HRM practices, for the purposes of this study we consider them as forming a single organisational culturerelated capability which we will call a 'Shared Strategic Vision' capability. 
In accord with other scholars [13, 14, 69], we suggest the alignment of a shared strategic vision capability and responsible HRM practices with the economic, social and environmental principles of sustainability is 'natural', and creates the potential for responsible HRM practices to be the 'tipping factor' that leads to the successful execution of CSR as a business strategy producing superior financial performance. Consequently, we propose the following hypothesis for testing:

Hypothesis 3: The association proposed in Hypothesis 2 is positively moderated by a firm's capability of shared strategic vision (SSV) in such a way that the positive interaction effect of EcEnvSOC and RHRM on financial performance is greater at high levels of SSV.

\section{Method}

The sample population comprised 1,278 Australian small firms, in the machinery and equipment manufacturing sector, drawn from a commercial database [70]. Small firms in this sector were attractive as a focus of study for three main reasons. First, while the role of responsible HRM practices in the implementation of CSR has been well researched in larger enterprises, smaller firms have received far less research attention [12]. Second, in theory the more flexible and less bureaucratic organisational structures of small firms might make such firms more proactive in their engagement in CSR [68]. Finally, the significant socioenvironmental impacts of firms in this sector (due to the nature of processes used to transform raw materials into finished manufacturing products) make them more likely to experience pressure to engage 'explicitly' in CSR activities.

This study employed a survey-based method for testing the research hypotheses. A survey questionnaire was developed based on the extant literature and existing published questionnaire items, and was pretested with owner-managers of three small firms to ensure content validity. As in small firms decision-making is often highly centralized, surveying a single experienced well-qualified informant is argued to better capture a firm's approach than surveying several informants [71, 72]. Hence, a single informant in each firm (either the business owner and/or CEO, managing director) was used in this study. The survey was administered by mail in April, 2009 (Time 1) and November, 2009 (Time 2), providing a sixmonth time lag between the measurements of predictor/moderators (EcEnvSoC, RHRM and SSV) and the dependent variable (financial performance). Such data collection allowed us to perform a bivariate correlation analysis between the same variable at the two different time points, thereby enabling reliability of the data to be evaluated. The six month delay in the data collection process also increased the likelihood that sufficient time would have elapsed to require informants to provide updated responses rather than simply repeat previous Time 1 responses.

The survey received 183 responses (from a possible 1,278 responses), representing a $14.3 \%$ response rate. After responses with missing data were eliminated, a total of 158 firms remained for analysis. Of the firms that did respond, the majority employed between 10 and 49 employees (75.3 \%) and had annual turnover between \$AU1 and \$AU10 million (66.5\%). Business owners $(67.1 \%)$ and respondents who had more than 5 year experience $(74.7 \%)$ in their firms were the majority of respondents. 
Based on previous literature $[73,74]$, it was recognised that data reported by single informants may be subject to common method bias. To test whether this was a problem, Harman's single-factor test was performed on the final sample through an exploratory factor analysis [75]. Results of the analysis showed no single general factor as accounting for most of the covariance in the variables, thus suggesting the interpretation of our results would not be confounded by common method bias. Moreover, an advantage of the moderated hierarchical regression analysis method employed in this study, was that common method effects are dealt with (along with main effects) before inspecting any interaction terms [76]. We also assessed non-response bias through the time-trend extrapolation procedure [77]; and no significant difference was detected between early and late respondents in terms of their demographic characteristics.

\subsection{Measures}

\subsubsection{Corporate Social Responsibility (EcEnvSoc) and RHRM}

In the absence of any publicly available data on CSR in small Australian manufacturing firms, respondents' perceptions of their firms were measured using an instrument comprising 27 survey items based on: the extant literature [18, 27, 28, 34, 59, 78]; and feedback received from pre-test participants. Respondents were asked to indicate the extent to which their firms voluntarily engaged in CSR activity compared to similar firms in their industry sector, using a five-point scale ( $1=$ 'not addressed issue at all' to $5=$ 'we are leaders on this issue'). A bivariate correlation analysis revealed the high correlation between Time 1 and Time 2 CSR data $(r=0.95)$, thus confirming our confidence in the reliability of the CSR scale.

An exploratory maximum likelihood factor analysis with varimax rotation was conducted and seven factors with eigenvalues greater than 1 emerged. The factors were related to different groups of CSR practices, and each of the 27 measured variables had a significant factor loading on one of these factors. Cronbach's alpha $(\alpha)$ ranged from 0.716 to 0.873 for each factor. A confirmatory factor analysis of items pertaining to the seven underlying identified factors (see Table 1 ) showed a good fit to the data $(\chi 2=358.67 ; \mathrm{df}=274$; RMSEA $=0.039 ; \mathrm{CFI}=0.99 ; \mathrm{IFI}=0.99 ;$ and $\mathrm{NNFI}=0.99$ ) and convergent validity (all standardized factor loadings above the value of 0.50 ).

Factors 1-6 (as shown in Table 1) were considered indicators of a single factor, which we labelled 'economic and environmental CSR, together with social CSR in the community' (EcEnvSoC). A second-order confirmatory factor analysis showed that the model fitted the data well ( $X 2=16.06 ; \mathrm{df}=11 ; \mathrm{RMSEA}=0.057 ; \mathrm{CFI}=0.99 ; \mathrm{IFI}=0.99 ;$ and NNFI = 0.99), and all six factors were significantly $(p<0.01)$ related to EcEnvSoC with standardized loadings ranging from 0.66 to 0.92 . The final measure of EcEnvSoC was a weighted average of the six factors using the standardized loadings obtained from the second-order confirmatory factor analysis, and a high score was indicative of a high degree of EcEnvSoC. Factor 7 (as shown in Table 1) was considered an indicator of 'responsible HRM practices' (RHRM) given the internal focus of the constituent items. The final measure of this variable was a weighted average of five underlying identified factors (SOC1-5) using the standardized loadings obtained from the confirmatory factor analysis, and a high score was indicative of a high degree of RHRM. 


\subsubsection{Shared Strategic Vision (SSV)}

A culture-related organisational capability was measured using a compilation of the three shared vision capability items from [78], and the three strategic proactivity capability items from [31].

All six items were presented as statements related to the firm, against each of which respondents were asked to rate their level of agreement on a six-point scale ( 1 = 'strongly disagree' to 6 = 'strongly agree') (see Table 2). The correlations obtained for each set of three items (shared vision $-r=0.89$; strategic proactivity $-r=0.89$ ) between Time 1 and Time 2 were high thus confirming our confidence in the reliability of each scale. As outlined earlier, for the purposes of this study, a shared vision capability (Cronbach's $\alpha=0.703$ ) and strategic proactivity capability (Cronbach's $\alpha=0.720$ ) were considered indicators of a single factor, which we labelled 'shared strategic vision' (SSV). A second-order confirmatory factor analysis revealed that the model had a good fit to the data $(\chi 2=12.04 ; \mathrm{df}=7$; $\mathrm{RMSEA}=$ 0.053; $\mathrm{CFI}=0.99 ; \mathrm{IFI}=0.98$; and NNFI $=0.98)$, and these two factors were significantly related to SSV (standardized loadings of shared vision $=0.69$ and of strategic proactivity $=$ $0.76, p<0.01$ ). The final measure of SSV was the average of the two factors using the standardized loadings obtained from the second-order confirmatory factor analysis, and a high score was indicative of a high degree of SSV.

Insert Table 2

\subsubsection{Financial Performance}

Our pre-test discussions with small business' owner managers revealed that respondents would be unlikely to provide specific objective data on their firm's financial performance due to its commercial-in-confidence in nature. In accordance with the literature that shows a high correlation and concurrent validity between objective and subjective data on performance, implying that both are valid when calculating a firm's financial performance $[79,80]$, we thus collected the respondents' perceptions on three financial performance items - return on assets, net profits to sales and liquidity (Cronbach's $\alpha=0.912$ ). These items were drawn from prior research [79, 81, 82]. Respondents were asked to rate their firm's financial performance, over the preceding six-month period compared to similar firms in their industry sector, using a five-point scale ( $1=$ 'much worse' to $5=$ 'much better') (see Table 3).

Insert Table 3

The factor score of financial performance was a weighted average (using the standardized loading) of these three items, with a high score being indicative of a high level of financial performance. In the absence of publicly available objective data, the high correlation obtained for financial performance between Time 1 and Time 2 surveys $(r=0.86)$ confirmed our confidence in the reliability of the financial performance scale.

\subsubsection{Control Variables}

Although we restricted our analysis to small firms, the breadth of this category suggested the need to use firm size to control for potential differences that may affect financial 
performance $[59,78]$. The size of a firm (measured by the number of employees employed on a regular basis) was thus controlled in this study. Furthermore, as our study was conducted during the global financial crisis (GFC), the potentially negative impact on firm performance of this external influence was treated as another control variable. This control variable was measured in terms of the extent to which general economic conditions had negatively impacted in the previous six-month period in relation to return on assets, net profits to sales and liquidity - using a five-point scale ( $1=$ 'no impact at all' to 5 = 'very high impact').

\section{Analysis and Results}

\subsection{Descriptive Statistics}

Analysis of the survey responses relating to CSR performance overall (EcEnvSoC plus RHRM) shows $39.5 \%$ of the sample firms reported the highest performance levels (i.e. ahead of, or leading, similar firms in their industry), with $31.5 \%$ reporting the lowest performance levels (i.e. not addressed at all or behind similar firms).

Looking at each specific dimension of CSR, the highest number of firms reporting they were ahead of, or leading, similar firms was $58.7 \%$ for RHRM, compared with $48.2 \%$ for economic CSR, $27.9 \%$ for environmental CSR, and $25.3 \%$ for social CSR in the community. In terms of leadership in each dimension, the reported emphasis differed, with economic CSR ranking highest at $14.7 \%$, followed by RHRM (11\%), and environmental and communityrelated social CSR ( $4.9 \%$ and $4.6 \%$ respectively). Within the RHRM dimension, the highest number of sample firms reported the highest performance (ahead of, or leading, similar firms) for item 'Improve employee health and safety' at $76.6 \%$, followed by item 'Creation of good work-life balance and family friendly employment' at $67.1 \%$. The remaining three RHRM items-'Investor in people', 'Employee participation in decision-making process' and 'Equal opportunities in workplace'-had $53.8 \%, 50.6 \%$ and $46.2 \%$ of the sample firms reporting the highest performance levels respectively. In relation to a SSV capability, $47.5 \%$ of the sample firms reported agreement (agreed or strongly agreed) regarding the existence of such a capability in their firm, with only $3.8 \%$ disagreeing (disagree or strongly disagree) about such a capability in their firm. In terms of financial performance, $40.5 \%$ of firms reported better or much better financial performance (compared to similar firms in their industry) for the reporting period.

\subsection{Hypotheses Testing}

Table 4 shows the means, standard deviations (SD) and correlations among the analysed variables. Estimated correlations between variables were well below the recommended cutoff of 0.7 , meaning that discriminant validity was established for the study constructs [83].

\section{Insert Table 4}

To test the research hypotheses, we followed the approach recommended by Baron and Kenny [84]; that is, by constructing separate independent variables for the predictor (EcEnvSoC), moderators (RHRM/SSV), two-way interaction term (multiplying EcEnvSoC with RHRM), and three-way interaction term (multiplying EcEnvSoC with RHRM and SSV). To prove moderation, the interaction term must be significant. There might also be significant main effects for the predictor and moderator variables but these effects are not directly 
relevant conceptually to testing the moderation hypothesis. Unlike the mediator-predictor relation (predictor being an antecedent to the mediator), moderators and predictors are at the same level in regard to their role as variables antecedent or exogenous to certain criterion effects [84].

In this study, we employed the moderated hierarchical regression analysis introducing moderator effects (interaction terms) in the final model [85]. Following the suggestion of previous research [86], we firstly mean-centered both the predictor and moderators prior to creating interaction terms in order to avoid multicollinearity. The variance inflation factor (VIF) for each of the regression coefficients was well below the recommended cut-off of 10 [87], with the VIF values for the final model ranging from 1.02 to 2.04 . This result indicated that multicollinearity did not affect the weights of the controls or the hypothesized variables [88].

Insert Table 5

Table 5 shows the results of moderated multiple regression models. In Model 1, only control variables (firm size and perceived GFC) were included, explaining $28 \%$ of the variance in financial performance $(F=32.79, p<0.001)$. Model 2 introduced the main effect of EcEnvSoC. The result showed that without considering other independent variables, EcEnvSoC had a main positive effect on financial performance, explaining an additional $16 \%$ of the variance in financial performance $(\mathrm{F}=28.56, p<0.001)$. RHRM and SSV were entered in Model 3 to examine their main effects. The results indicated that by controlling for the main effect of EcEnvSoC, both RHRM and SSV had no main effect on financial performance, with no significant additional variance explained by adding these two variables ( $\Delta$ Adjusted R2 = 0.02). In Model 4, the two way interaction term of EcEnvSoC with RHRM and the threeway interaction term of EcEnvSoC, RHRM and SSV were added. The model was significant $(F=20.39, p<0.001)$ and explained $57 \%$ of the variance in financial performance. It also represented a significant improvement over Model 3 as indicated by a change in adjusted R2 from 0.46 to $0.57(p<0.001)$.

As shown for Model 4 of Table 5 , the coefficient for EcEnvSoC was significant and positive ( $b$ $=0.21, p<0.01)$, indicating the existence of a main positive effect of EcEnvSoC on financial performance. Hence, Hypothesis 1 was supported. The two-way interaction of EcEnvSoC with RHRM was positive and statistically significant $(b=0.29, p<0.01)$, indicating that the benefits of EcEnvSoC for financial performance increased at high levels of RHRM, and thereby providing support for Hypothesis 2. The three-way interaction of EcEnvSoC, RHRM and SSV was positively significant $(b=0.37, p<0.001)$, suggesting that the positive interactive effect of EcEnvSoC and RHRM on financial performance was stronger at high levels of SSV, and thus supporting Hypothesis 3. With regard to the control variables, firm size was found to be positively associated with financial performance $(b=0.20, p<0.01)$, while a negative association was observed between the perceived GFC and financial performance $(b=-0.40, p<0.001)$.

In order to explore the nature of these interactions further, we computed simple slopes and graphed the interactions, using high (1 SD above the mean) and low (1 SD below the mean) levels of the moderator. Figure 2 illustrates the effect of EcEnvSoC on financial performance 
moderated by RHRM, by showing that at high levels of RHRM the association between EcEnvSoC and financial performance was positive and strong (simple slope $=0.41, p<0.05$ ). However, the strength of this association was greatly diminished and became insignificant at low levels of RHRM (simple slope $=0.02, p=0.84$ ), thus providing further support for Hypothesis 2.

\section{Insert Figure 2}

Figure 3 shows the effect of the interaction between EcEnvSoC and RHRM on financial performance moderated by SSV. Based on this figure, the association between EcEnvSoC interacting with RHRM and financial performance was positive and strong at high levels of SSV (simple slope $=0.51, p<0.01$ ), but the strength of this association greatly declined and became insignificant at low levels of SSV (simple slope $=0.08, p=0.69$ ), thereby providing further support for Hypothesis 3.

\section{Insert Figure 3}

\section{Discussion}

Our aim for this research has been to examine how and with what impact a firm's HRM practices-considered in terms of responsible HRM practices (RHRM) and a culture-related capability of shared strategic vision (SSV) - can contribute to creating the potential for the other combined elements of CSR (economic and environmental CSR together with social CSR in the community: EcEnvSoC) that result in competitive advantage and superior financial returns for the firm. Consistent with our hypotheses, we have found that RHRM practices and, more importantly the RHRM-SSV interaction, positively moderate the effect of EcEnvSoC on firm financial performance. In other words, the financial benefits of EcEnvSoC increase at high levels of RHRM, and such benefits are likely to be greater when RHRM interacts together with a SSV capability.

The study findings provide empirical evidence for the importance of RHRM practices as fundamental to the achievement of sustainable financial and socially responsible business outcomes for small firms. These findings are in line with previous research $[6,13,14,41]$, and lend support to the argument of Gond and colleagues [52] that RHRM plays a central role as a strategic piece of CSR for sustaining corporate orientation towards a 'triple bottom line'. As suggested by previous research [89], RHRM practices, such as engaging employees and providing values-oriented training and employee development opportunities, can complement environmental-related CSR by building commitment to environmental values and improving the necessary technological skills for adopting such activity. Complementarity may also create an impetus in the firm that drives the transition towards economic-related CSR [90]; properly designed RHRM can trigger innovations that improve production efficiency and lower the cost of a product and that contribute positively to a firm's financial performance.

Our finding in relation to the positive moderating effect of a SSV capability also confirms the importance of the strategic integration of collective values about organisational goals and of the exploitation of new business opportunities in generating a better effective implementation of RHRM that promotes financial performance in small firms. This finding is 
consistent with other previous empirical and theoretical research relevant to the SME context $[25,26,64,78]$, as well as in line with a primary tenet in RBV theory that a firm's capabilities are fundamental drivers of competitive advantage and superior performance [54].

It is also of interest to note-based on our descriptive statistics showing the 'moderate-tohigh' RHRM adoption rate among the sample firms (nearly $60 \%$ reporting ahead of/leading similar firms on RHRM overall) - that small firms are more likely to embrace the adoption of RHRM (albeit perhaps on an ad hoc basis, rather than as part of a deliberate strategic approach) more widely than might be expected given the size-related resource constraints under which many operate [91, 92, 94-96]. In this study, the weight given to RHRM by the majority of firms is found to be greater than that given to performance in regard to economic-related CSR practices. This result may reflect recognition of the importance of employees to the achievement of a firm's business objectives generally [12], and lends support to the notion that the value of CSR becomes debased and only an exercise in public relations when employees are not fully engaged [97].

By focusing on specific types of RHRM, 'employee health and safety' and 'work-life balance and family friendly employment' have the highest performance levels reported by the majority of the sample firms ( $77 \%$ and $67 \%$ respectively). These results may reflect the Australian institutional profile (see [98] for extensive discussion of the 'institutional profile' concept) where the existing industrial regulatory framework, the values/beliefs about good management practices held by owner-managers, and a prevalence of ad hoc arrangements developed in response to requests from individual employees, make it more common for small-firm workplaces in Australia to actively implement and promote these certain types of RHRM.

The descriptive analysis of our survey data also indicates that only slightly more than half of firms report the highest performance levels in 'investing in employees' and 'employee participation in decision-making' (54\% and $51 \%$ respectively), whilst less than half of them perform at the highest levels in terms of 'equal opportunities' (46\%). Taking investment in employees first, although there is no agreement in the literature regarding the level of training provided by small firms [99], our finding of a moderate adoption rate accords with published research in the UK context [5, 92], which may reflect the difficulties of measuring 'informal' training provision (e.g. on-the-job training) in small firms causing the true level of training provision to be underreported [100].

In relation to employee participation, although our finding of a 'moderate-tolow' adoption rate aligns with the results of previous research [10] that Australian SMEs have been reluctant to use management practices that support employee participation, it would be misleading to interpret this finding without considering the existence of a SSV capabilitywhich relates to employees being able to influence the way to work and the objectives of the firm, and to freely contribute their points of view about how to manage the firm smoothly-in the sample firms. Evidence presented in this study of only $4 \%$ of firms reporting disagreement regarding the existence of such a capability in their firms, suggest that the principle of employee participation is, in fact, highly accepted amongst small firms in our sample, but they might not have 'formal' employee-participation policies in place. 
This explanation is supported by the findings from the 2004 Workplace Employment Relations Survey (WERS) in the UK indicating that in contrast to employees in medium and large firms, the majority of employees in small firms report high satisfaction (good or very good) with their workplace manager in keeping them informed about, and participating in, changes to the running of the business, changes in staffing and changes in their job [99].

Lastly, whilst on the one hand the low rate of adopting equal opportunity practices found in this study may indicate that such practices are less common in workplaces in Australian small firms, on the other hand it may reflect a lack of formal written equal opportunity policies among the sample firms to carry out a range of monitoring activities to assess whether employment practices have any discriminatory effects. Our assumption is confirmed by the results from the 2007 WERS showing that workplaces in smaller firms make less use of equal opportunity practices than those in larger firms due to a lack of policy formality, but even so, employees in smaller firms are more likely to experience fair treatment in their workplace than those in larger firms [99].

\section{Conclusions}

The study has significant practical management implications. The empirical evidence presented in this study highlights the critical role of responsible HRM practices plus a culture-related capability in successful implementation of CSR that promotes financial performance of small firms. It appears, based on our findings, that the borders of HRM and CSR are increasingly blurred [52], where responsible HRM practices reported by small firms are informed by the principles of CSR and the need to enhance financial performance while creating the sustainable outcomes of value increasingly required of business. In particular, the study findings indicate the need for managers, who wish their small firm to remain financially competitive from their CSR efforts, to be aware of the importance of implementing CSR policies with RHRM practices that reflect and fulfill employees' needs and which avoid adopting a paternalistic approach that neglects the employees' perspective. It is also worthwhile to note that unlike large firms, there seems to be a lack of formality in HRM practices in small firms that provide an important benefit. Workplaces which are part of small firms tend to have high levels of informality and familial ties that can help to engender trust and reciprocity in manager-employee interactions.

In common with most research, this study has some limitations. First, the sample size was small which could reduce the reliability and stability of parameter estimates. Research suggests that the detection of moderating effects is often constrained by small sample size [101]. However, given that all of our hypotheses were supported, we can be confident in the robustness of our findings. Second, difficulties in generalizing results to other industry sectors and to other economies should be acknowledged. Third, the findings are limited by the self-reported nature of the data collection process. Finally, although we used the 6month time lag in data collection to allow for temporal ordering of independent/moderating and dependent variables, this time gap was insufficient time to confirm deterministic causation. Future research might include a quasi-experimental longitudinal study over a longer time period with a larger sample size to evaluate the RHRMSSV interaction effects with CSR on financial performance, thereby allowing for broader generalizability in findings. Linking the model variables to multiple data sources that take into account objective 
measures would further extend our understanding of how responsible HRM practices and capabilities could strengthen the CSR-performance relationship. 


\section{References}

1. Dunphy, D. (2003). Corporate sustainability: Challenge to managerial orthodoxies. Journal of the Australian and New Zealand Academy of Management, 9(1), 2-11.

2. Jenkins, H. (2009). A business opportunity model of corporate social responsibility for small-and medium-sized enterprises. Business Ethics: A European Review, 18(1), 21-36.

3. Porter, M. E., \& Kramer, M. R. (2006). Strategy and society: The link between competitive advantage and corporate social responsibility. Harvard Business Review, 84(12), 78-92.

4. Gollan, P. J. (2000). Human resources, capabilities, and sustainability. In D. Dunphy, J. Benveniste, A. Griffiths, \& P. Sutton (Eds.), Sustainability: The corporate challenge of the 21st century (pp. 55-77). Sydney: Allen and Unwin.

5. Hughes, M., Keddie, V., Webb, P., \& Corney, M. (2002). Working towards skills: perspectives in workforce development in SMEs. London: Learning and Skills Development Agency.

6. Roehling, M. V., Boswell, W. R., Caligiuri, P., Feldman, D., Graham, M. E., Guthrie, J. P., et al. (2005). The future of HR management: Research needs and directions. Human Resource Management, 44(2), 207-216.

7. Stone, R. (2011). Human resource management (7th ed.). Milton: Willey.

8. Barrett, R., \& Buttigieg, D. (1999). Trade unions and small firms: Is it size that counts? Labour and Industry, 9(3), 41-55.

9. Bartram, T. (2005). Small firms, big ideas: The adoption of human resource management in Australian small firms. Asia Pacific Journal of Human Resources, 43(1), 137-154.

10. Wiesner, R., \& McDonald, J. (2001). Bleak house or bright prospect? Human resource management in Australian SMES. Asia Pacific Journal of Human Resources, 39(2), 31-53.

11. Heneman, R. L., Tansky, J. W., \& Camp, S. M. (2000). Human resource management practices in small and medium-sized enterprises: Unanswered questions and future research perspectives. Entrepreneurship Theory and Practice, 25(1), 11-26.

12. Mankelow, G. (2008). Social responsibility paradox of small business human resource management practices. The International Journal of Human Resource Management, 19(12), 2171-2181.

13. Gollan, P. J. (2006). Sustainable strategies towards human resources: A way forward. In D. Marinova, D. Annandale, \& J. Phillimore (Eds.), International handbook on environmental technology management (pp. 104-118). London: Edward Elgar.

14. Jabbour, C. J. C., \& Santos, F. C. A. (2008). Relationships between human resources dimensions and environmental management in companies: Proposal of a model. Journal of Cleaner Production, 16, 51-58. 
15. Martin-Tapia, I., Aragon-Correa, J. A., \& Llamas-Sanchez, R. (2008). The relationship between high performance work systems and proactive environmental management. In R. Wustenhagen, J. Hamschmidt, S. Sharma, \& M. Starik (Eds.), Sustainable innovation and entrepreneurship (pp. 197-224). Cheltenham: Edward Elgar.

16. Vickers, M. (2005). Business ethics and the HR role: Past, present, and future. Human Resource Planning, 28(1), 26-32.

17. Montiel, I. (2008). Corporate social responsibility and corporate sustainability: Separate pasts, common futures. Organization \& Environment, 21(3), 245-269.

18. Commission, European. (2003). Responsible entrepreneurship: A collection of good practice cases among small and medium-sized enterprises across Europe. Luxembourg: European Commission.

19. Aragon-Correa, J. A., \& Sharma, S. (2003). A contingent resource-based view of proactive corporate environmental strategy. Academy of Management Review, 28(1), 71-88.

20. Benn, S., Dunphy, D., \& Griffiths, A. (2006). Enabling change for corporate sustainability: An integrated perspective. Australasian Journal of Environmental Management, 13(3), 156165.

21. Du, S., Bhattacharya, C. B., \& Sen, S. (2007). Reaping relational rewards from corporate social responsibility: The role of competitive positioning. International Journal of Research in Marketing, 24(3), 224-241.

22. Groza, M. D., Pronschinske, M. R., \& Walker, M. (2011). Perceived organizational motives and consumer responses to proactive and reactive CSR. Journal of Business Ethics, 102, 639-652.

23. Klassen, R. D., \& Whybark, D. C. (1999). The impact of environmental technologies on manufacturing performance. Academy of Management Journal, 42(6), 599-615.

24. Sharma, S., \& Vredenburg, H. (1998). Proactive corporate environmental strategy and the development of competitively valuable organizational capabilities. Strategic Management Journal, 19(8), 729-753.

25. Torugsa, N. A., O'Donohue, W., \& Hecker, R. (2012). Capabilities, proactive CSR and financial performance in SMEs: Empirical evidence from an Australian manufacturing industry sector. Journal of Business Ethics, 109(4), 483-500.

26. Torugsa, N. A., O'Donohue, W., \& Hecker, R. (2013). Proactive CSR: An empirical analysis of the role of its economic, social and environmental dimensions on the association between capabilities and performance. Journal of Business Ethics, 115(2), 383-402.

27. Bansal, P. (2005). Evolving sustainably: A longitudinal study of corporate sustainable development. Strategic Management Journal, 26(3), 197-218.

28. Dyllick, T., \& Hockerts, K. (2002). Beyond the business case for corporate sustainability. Business Strategy and the Environment, 11(2), 130-141. 
29. Willard, B. (2005). The sustainability advantage: Seven business case benefits of a triple bottom line. Canada: New Society Publisher.

30. Walley, N., \& Whitehead, B. (1994). It's not easy being green. Harvard Business Review, 72(3), 46-52.

31. Aragon-Correa, J. A. (1998). Strategic proactivity and firm approach to the natural environment. Academy of Management Journal, 41(5), 556-567.

32. Brammer, S., \& Millington, A. (2006). Firm size, organizational visibility and corporate philanthropy: An empirical analysis. Business Ethics: A European Review, 15(1), 6-18.

33. Lepoutre, J., \& Heene, A. (2006). Investigating the impact of firm size on small business social responsibility: A critical review. Journal of Business Ethics, 67(3), 257-273.

34. Jenkins, H. (2006). Small business champions for corporate social responsibility. Journal of Business Ethics, 67(3), 241-256.

35. Harrison, J. G., \& Freeman, R. E. (1999). Stakeholders, social responsibility and performance: Empirical evidence and theoretical perspectives. Academy of Management Journal, 42(5), 479-485.

36. Hart, S. L., \& Ahuja, G. (1996). Does it pay to be green?: An empirical examination of the relationship between emission reduction and firm performance. Business Strategy and the Environment, 5, 30-37.

37. Mackey, A., Mackey, T. B., \& Barney, J. B. (2007). Corporate social responsibility and firm performance: Investor preferences and corporate strategies. Academy of Management Review, 32(3), 817-835.

38. Hammann, E., Habisch, A., \& Pechlaner, H. (2009). Values that create value: Socially responsible business practices in SMEs-empirical evidence from German companies.

Business Ethics: A European Review, 18(1), 37-51.

39. Jamrog, J., Vickers, M., \& Bear, D. (2006). Building and sustaining a culture that supports innovation. Human Resource Planning, 29(3), 9-19.

40. Matthews, J. (2002). Innovation in Australian small to medium enterprises:

Contributions from strategic human resource management. Asia Pacific Journal of Human Resources, 40(2), 193-204.

41. Chew, I. K. H., \& Sharma, B. (2005). The effects of culture and HRM practices on firm performance: Empirical evidence from Singapore. International Journal of Manpower, 26(6), 560-581.

42. Laursen, K., \& Foss, N. J. (2003). New HRM practices, complementarities, and the impact on innovation performance. Cambridge Journal of Economics, 27(2), 243-263.

43. Fernandez, E., Junquera, B., \& Ordiz, M. (2003). Organizational culture and human resources in the environmental issue: A review of the literature. The International of Human Resource Management, 14(4), 634-656. 
44. Rothenberg, S. (2003). Knowledge content and worker participation in environmental management at NUMMI. Journal of Management Studies, 40(7), 1783-1802.

45. Berry, M. A., \& Rondinelli, D. A. (1998). Proactive corporate environment management: A new industrial revolution. Academy of Management Executive, 12(2), 38-50.

46. Bianchi, R., \& Noci, G. (1998). Greening SMEs' competitiveness. Small Business Economics, 11(3), 269-281.

47. Ramus, C. A., \& Steger, U. (2000). The roles of supervisory support behaviors and environmental policy in employee 'Ecoinitiatives' at leading-edge European companies. Academy of Management Journal, 43(4), 605-626.

48. Greenwood, M. R. (2002). Ethics and HRM: A review and conceptual analysis. Journal of Business Ethics, 36, 261-278.

49. Legge, K. (1998). The morality of HRM. In C. Mabey, D. Skinner, \& T. Clark (Eds.), Experiencing human resource management (pp. 14-32). London: Sage.

50. Winstanley, D., Woodall, J., \& Heery, E. (1996). Business ethics and human resource management themes and issues. Personnel Review, 25(6), 5-12.

51. Shen, J., \& Zhu, C. J. (2011). Effects of socially responsible human resource management on employee organizational commitment. The International Journal of Human Resource Management, 22(15), 3020-3035.

52. Gond, J. P., Igalens, J., Swaen, V., \& Akremi, A. E. (2011). The human resource contribution to responsible leadership: An exploration of the CSR-HR interface. Journal of Business Ethics, 98, 115-132.

53. Barney, J. B. (1986). Types of competition and the theory of strategy: Toward an integrative framework. Academy of Management Review, 11(4), 791-800.

54. Barney, J. B. (1991). Firm resources and sustained competitive advantage. Journal of Management, 17(1), 99-120.

55. Andersson, L. M., \& Bateman, T. S. (2000). Individual environmental initiative: Championing natural environmental issues in US business organizations. Academy of Management Journal, 43, 548-570.

56. Hart, S. L. (1995). A natural-resource-based view of the firm. Academy of Management Review, 20(4), 986-1014.

57. Buysse, K., \& Verbeke, A. (2003). Proactive environmental strategies: A stakeholder management perspective. Strategic Management Journal, 24(5), 453-470.

58. Christmann, P. (2000). Effects of 'best practices' of environmental management on cost advantage: the role of complementary assets. Academy of Management Journal, 43(4), 663-680. 
59. Sharma, S., Aragon-Correa, J. A., \& Rueda-Manzanares, A. (2007). The contingent influence of organizational capabilities on proactive environmental strategy in the service sector: An analysis of North American and European ski resort. Canadian Journal of Administrative Science, 24(4), 268-283.

60. Marcus, A. A., \& Geffen, D. (1998). The dialectics of competency acquisition: Pollution prevention in electric generation. Strategic Management Journal, 19, 1145-1168.

61. Boxall, P., \& Purcell, J. (2003). Strategy and human resource management. Hampshire: Palgrave Macmillan.

62. Tsai, W., \& Ghoshal, S. (1998). Social capital and value creation: The role of intrafirm networks. Academy of Management Journal, 41(4), 464-476.

63. Campbell, A., \& Yeung, S. (1991). Creating a sense of mission. Long Range Planning, 24(4), 10-20.

64. Pfeffer, J. (2005). Changing mental models: HR's most important task. Human Resource Management, 44(2), 123-128.

65. Roberts, R., \& Hirsch, P. (2005). Evolution and revolution in the twenty-first century: Rules for organizations and managing human resources. Human Resource Management, 44(2), 171-176.

66. Chen, M., \& Hambrick, D. C. (1995). Speed, stealth, and selective attach: How small firms differ from large firms in competitive behavior. Academy of Management Journal, 38(2), 453-482.

67. Covin, J. G., \& Slevin, D. P. (1990). New venture strategic posture, structure and performance: An industry life cycle analysis. Journal of Business Venturing, 5(2), 123-135.

68. Veliyath, R., \& Shortell, S. M. (1993). Strategic orientation, strategic planning system characteristics and performance. Journal of Management Studies, 30(3), 359-381.

69. Boudreau, J. W., \& Ramstad, P. M. (2005). Talentship, talent segmentation, and sustainability: A new HR decision science paradigm for a new strategy definition. Human Resource Management, 44(2), 129-136.

70. Dun and Bradstreet. (2009). Australia's premier source of business intelligence just got even better. Australia: Dun and Bradstreet.

71. Chandler, G. N., \& Hanks, S. H. (1993). Measuring the performance of emerging business: A validation study. Journal of Business Venturing, 8(5), 391-408.

72. Lyon, D. W., Lumpkin, G. T., \& Dess, G. G. (2000). Enhancing entrepreneurial orientation research: Operationalizing and measuring a key strategic decision making process. Journal of Management, 26(5), 1055-1085.

73. Gardner, T. M., \& Wright, P. M. (2009). Implicit human resource management theory: A potential threat to the internal validity of human resource practice measures. The International Journal of Human Resource Management, 20(1), 57-74. 
74. Podsakoff, P. M., MacKenzie, S. M., Lee, J., \& Podsakoff, N. P. (2003). Common method variance in behavioral research: A critical review of the literature and recommended remedies. Journal of Applied Psychology, 88(5), 879-903.

75. Podsakoff, P. M., \& Organ, D. W. (1986). Self reports in organizational research: Problems and prospects. Journal of Management, 12(4), 531-544.

76. Pierce, J. L., Gardner, D. G., Dunham, R. B., \& Cummings, L. L. (1993). Moderation by organization-based self-esteem of role condition-employee response relationships. Academy of Management Journal, 36(2), 271-288.

77. Armstrong, J., \& Overton, T. (1977). Estimating nonresponse bias in mail surveys. Journal of Marketing Research, 14, 396-402.

78. Aragon-Correa, J. A., Hurtado-Torres, N., Sharma, S., \& Garcia-Morales, J. V. (2008). Environmental strategy and performance in small firms: A resource-based perspective. Journal of Environmental Management, 86(1), 88-103.

79. Dess, G. G., \& Robinson, R. B. (1984). Measuring organizational performance in the absence of objective measures: The case of the privately-held firm and conglomerate business unit. Strategic Management Journal, 5(3), 265-275.

80. Homburg, C., Krohmer, H., \& Workman, J. P. (1999). Strategic consensus and performance: The role of strategy type and market-related dynamism. Strategic Management Journal, 20(4), 339-357.

81. Ansoff, H. I. (1965). Corporate strategy. New York: McGraw-Hill.

82. Lin, H. P., Huang, W. C., Chen, H. F., \& Ke, Y. P. (2011). An empirical study of Taiwan's hospital foundation investment in corporate social responsibility and financial performance. World Academy of Science, Engineering and Technology, 78, 345-349.

83. Pallant, J. (2007). SPSS: survival manual: A step-by-step guide to data analysis using SPSS for windows, Version 15. New South Wales: Allen \& Unwin.

84. Baron, R. M., \& Kenny, D. A. (1986). The moderator-mediator variable distinction in social psychological research: Conceptual, strategic and statistical considerations. Journal of Personality and Social Psychology, 51, 1173-1182.

85. Cohen, J., \& Cohen, P. (1983). Applied multiple regression/correlation analysis for the behavioural sciences. Hillsdale: Lawrence Erlbaum.

86. Aiken, L. S., \& West, S. G. (1991). Multiple regression: Testing and interpreting interactions. Newbury Park: Sage.

87. Mason, C., \& Perreault, W. (1991). Collinearity, power, and interpretation of multiple regression analysis. Journal of Marketing Research, 28, 268-280.

88. Neter, J., Wasserman, W., \& Kutner, M. H. (1985). Applied linear statistical models: Regression, analysis of variance, and experimental design. Homewood: Richard D. Irwin. 
89. Graafland, J., van de Ven, B., \& Stoffele, N. (2003). Strategies and instruments for organising CSR by small and large businesses in the Netherlands. Journal of Business Ethics, 47(1), 45-60.

90. Chang, D., \& Kuo, L. R. (2008). The effects of sustainable development on firms' financial performance-an empirical approach. Sustainable Development, 16, 365-380.

91. Bacon, N., Ackers, P., Storey, J., \& Coates, D. (1996). 'It's a small world: Managing human resources in small business. The International Journal of Human Resource Management, 7 , 82-100.

92. Cassell, C., Nadin, S., Gray, M., \& Clegg, C. (2002). Exploring human resource management practices in small and medium sized enterprises. Personnel Review, 31, 671692.

93. Cohen, J. (1988). Statistical power analysis for the behavioral sciences. Hillsdale: Lawrence Erlbaum.

94. de Kok, J., \& Uhlaner, L. (2001). Organisation context and human resource management in the small firm. Small Business Economics, 17, 273-291.

95. Duberley, J., \& Walley, P. (1995). Assessing the adoption of HRM by small and medium sized manufacturing organisations. The International Journal of Human Resource Management, 6, 891-909.

96. Wiesner, R., \& Innes, P. (2010). Bleak house or bright prospect? Human resource management in Australian SMEs over 1998-2008. Asia Pacific Journal of Human Resources, $48,151-183$.

97. Mees, A., \& Bonham, J. (2004). Corporate social responsibility belongs with HR. Canadian HR Reporter, 17(7), 11-13.

98. Kostova, T., \& Roth, K. (2002). Adoption of an organizational practice by subsidiaries of multinational corporations: Institutional and relational effects. Academy of Management, 45(1), 215-233.

99. Forth, J., Bewley, H., \& Bryson, A. (2004). Small and medium-sized enterprises: Findings from the 2004 workplace employment relations survey. London: Department of Trade and Industry.

100. Patton, D., Marlow, S., \& Hannon, P. (2000). The relationship between training and small firm performance: Research frameworks and lost quests. International Small Business Journal, 19(1), 11-27. 